\title{
Optimization of Industrial Emission Analysist by Reading Sensor Output Voltage
}

\author{
Al Mahdali ${ }^{1}$, Andani Achmad ${ }^{2}$, Ansar Suyuti $^{3}$ \\ 1,2,3 Department of Electrical Engineering, Faculty of Engineering, Universitas Hasanuddin \\ Makassar, Indonesia. 92119 \\ \{almahdalisyafruddin@gmail.com¹,andani@unhas.ac.id², ansarsuyuti@gmail.com³
}

\begin{abstract}
Supervision of industrial emissions in big cities is very important. Providing oversight of industrial emissions will provide benefits in maintaining excessive air pollution. In this condition we can see that the importance of reducing air pollution in this industial era. In current conditions, the industry uses an emission reading device whose size is not very practical because of its large size. Design a more optimal program by utilizing the role of gas sensors in reading several types of gas. In reading the gas value, a reading and calibration process is carried out using matlab and optimizing the program made in reading the value of the amount of gas emission content in PPM (Part per Million) units. With the method we are using now, it will be a more practical method without reducing the efficiency of the industry's emissions measurement.
\end{abstract}

Keywords: Sensor, Matlab, Object Oriented Programming, Emission, Industry.

\section{Introduction}

The air quality is not just any other parameter but a salutary creator. Only PREDICTING state or city temperature isn't enough. There is a need to enlighten the individuals by ANALYZING the air quality and providing useful INSIGHTS from town to town, from area to area, from park to park and lastly from human to human[1].

Air quality degradation comes as no new problem and a number of steps have been taken to avoid it. The knowledge of the quality of air in immediate environment help people make smarter decisions and choices for their everyday life activities [2]. For example, one can make better decisions about which route to travel from so that he/she is exposed to less pollution or, if a person is asthmatic he/she can buy a home in a place where there is less pollution.

Sysstem for air monitoring control is requred for activity analysis and their impact on nature of the power plants, mining sector, oil and gas industry, etc. Basically, determination of air and water quality relies on estimation of values of some important and indicative parameters [3-5].

The air quality depends of the air temperature, humidity, radiation, activity level, air flow and presence of volatile organic compounds (VOC) $[15,16]$. 


\section{A. Toxic gases in regular environment}

1) Carbon dioxide:

Carbon dioxide (CO2), a colorless gas having a faint, sharp odor and a sour taste. It is a minor component of Earth's atmosphere formed in combustion of carboncontaining materials, in fermentation, and in respiration of animals and employed by plants in the photosynthesis of carbohydrates. The presence of the $\mathrm{CO} 2$ gas in the atmosphere keeps some of the radiant energy received by Earth from being returned to space, therefore, produces the so-called greenhouse effect. Industrially, it is recovered for numerous diverse applications from flue gases, as a byproduct of the preparation of hydrogen for synthesis of ammonia, from limekilns, and from other sources [6]. The CO2 gas can cause headaches, sleepiness, dizziness, unconsciousness and serious oxygen deprivation that leads to death.

\section{2) Carbon monoxide:}

Carbon monoxide (CO) is a colorless, odorless gas that can be harmful by inhaling in large amounts. $\mathrm{CO}$ is released when something is burned. The greatest sources of $\mathrm{CO}$ in outdoor air are cars, trucks and other vehicles or machinery that burn fossil fuels. A variety of items in your home such as unvented kerosene and gas space heaters, leaking chimneys and furnaces, and gas stoves also release $\mathrm{CO}$ and can affect the quality of indoor air. Breathing air with a high concentration of $\mathrm{CO}$ reduces the amount of oxygen that can be transported in the blood stream to critical organs like the heart and brain. In addition, at very high levels, which are possible indoors or in other enclosed environments, carbon monoxide (CO) can cause dizziness, confusion, unconsciousness and death. B. Safe Levels of CO2 and $\mathrm{CO}$ in rooms According to KANE International the safe levels of carbon monoxide (CO) and carbon dioxide $(\mathrm{CO} 2)$ in rooms are shown in TABLE I and TABLE II respectively [7].

Table 1. Effects Of Carbon Dioxide Gas For Change Of Amount

\begin{tabular}{|l|l|}
\hline Level (ppm) & \multicolumn{1}{c|}{ Effects } \\
\hline $250-350$ & $\begin{array}{l}\text { Normal background concentration in outdoor ambient } \\
\text { air }\end{array}$ \\
\hline $350-1,000$ & $\begin{array}{l}\text { Concentrations typical of occupied indoor spaces with } \\
\text { good air exchange }\end{array}$ \\
\hline $1,000-2,000$ & Complaints of drowsiness and poor air. \\
\hline $2,000-5,000$ & $\begin{array}{l}\text { Headaches, sleepiness and stagnant, stale, stuffy air. } \\
\text { Poor concentration, loss of attention, increased heart } \\
\text { rate, and slight nausea may also be present. }\end{array}$ \\
\hline 5,000 & $\begin{array}{l}\text { Workplace exposure limit (as 8-hour TWA) in most } \\
\text { jurisdictions. }\end{array}$ \\
\hline$>40,000$ & $\begin{array}{l}\text { Exposure may lead to serious oxygen deprivation } \\
\text { resulting in permanent brain damage, coma, even death }\end{array}$ \\
\hline
\end{tabular}


Table 2. Effects Of Carbon Monoxide Gas For Change Of Amount

\begin{tabular}{|l|l|}
\hline \multicolumn{1}{|c|}{ Level (ppm) } & \multicolumn{1}{c|}{ Effects } \\
\hline 9 & CO Max prolonged exposure (ASHRAE standard) \\
\hline 35 & CO Max exposure for 8 hour work day (OSHA) \\
\hline 800 & CO Death within 2 to 3 hours \\
\hline 12,800 & CO Death within I to 3 minutes \\
\hline
\end{tabular}

\section{Material and Methods}

\section{1 Material}

The block diagram of the proposed system is shown in Fig. 1. The system mainly consists of three steps. The first one is sensing and measurement circuit. Second one is microcontroller circuit The third one is the unit.

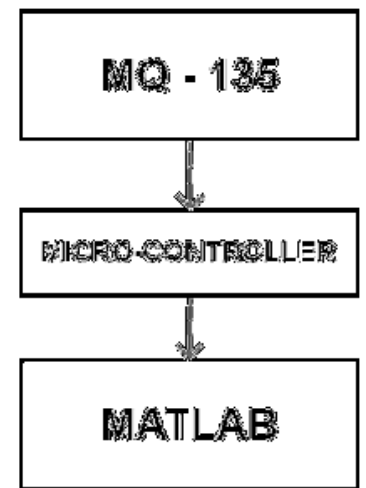

Fig 1. Block Diagram of the System

\section{A. MQ-135 Sensor}

The MQ-135 Gas sensors are used in air quality control equipment's and are suitable for detecting or measuring of NH3, NOx, Alcohol, Benzene, Smoke and CO2. [8]

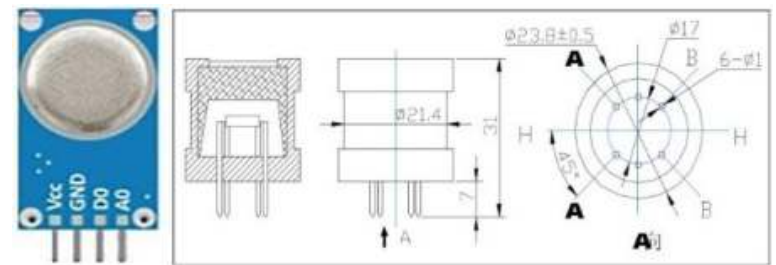

Fig 2. Structure of MQ-135 Sensor

It has the impressive sensitivity of variety natural gases such as Carbon monoxide (CO), Carbon dioxide (CO2), Phenol (C6H6O), Toluene (C7H8), Benzene (C6H6), and air. The Sensitivity characteristics of the MQ-135 sensor for various gases has been plotted and shown in Fig. 5. [9] 
Air quality click board from mikroElektronika [10] carries an MQ-135 sensor for detecting poisonous gases that impact air quality in homes and offices. The gas sensing layer on the sensor unit is made of tin dioxide $(\mathrm{SnO} 2)$, which has lower conductivity in clean air. The conductivity increases with air pollution. The sensor reacts to ammonia (NH3), nitrogen oxides (NOx), benzene, smoke, CO2 and other harmful gases [12,13].

The primary purpose of this sensor is to measure air quality for both indoor (offices/buildings) as well as outdoor (parks/dump yards) etc. areas especially in terms of providing particles per million (ppm) value for $\mathrm{NH} 3, \mathrm{NOx}$, alcohol, Benzene, smoke, CO2 etc [14].

The features which make them rigid and stable working machines are a simple driver circuit accompanied by a long life of working, a wide detecting scope and fast and high sensitivity response time [15].The different sensitivity characteristics of MQ-135 are mentioned in table 3 and the various material used in making different parts of the sensor are mentioned below in table 4 . Also, the figure 4 represents the circuit of MQ-135.

\section{B. Arduino Uno R3}

Arduino Uno is a microcontroller board based on the Atmega328P (datasheet). It has 14 digital input/output pins (of which 6 can be used as PWM outputs), 6 analog inputs, a $16 \mathrm{MHz}$ quartz crystal, a USB connection, a power jack, an ICSP header and a reset button. It contains everything needed to support the microcontroller; simply connect it to a computer with a USB cable or power it with a AC-to-DC adapter or battery to get started.

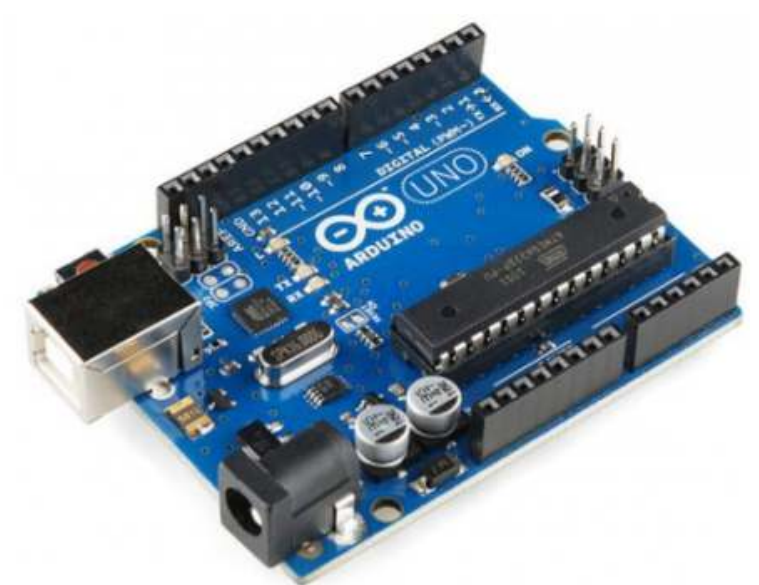

Fig 3. Arduino Uno R3

Most Arduino boards are calibrated to work at a linear regulation of $5 \mathrm{~V}$ and $16 \mathrm{MHz}$ clock speed. Arduino Uno, the most common of the family uses the concept of USB-to-serial conversion and has 6 analog pins and 14 digital I/O pins $[10,11]$

Table 3. Arduino Uno Overview

Microcontroller

Operating Voltage

Input Voltage (recommended)
Atmega328P 


\begin{tabular}{|cc}
\hline Input Voltage (limit) & $6-20 \mathrm{~V}$ \\
Digital I/O Pins & 14 (of which 6 provide PWM output) \\
\hline PWM Digital I/O Pins & 6 \\
Analog Input Pins & $20 \mathrm{~mA}$ \\
DC Current per I/O Pin & $50 \mathrm{~mA}$ \\
DC Current for 3.3V Pin & bootloader \\
Flash Memory & $2 \mathrm{~KB}$ (Atmega328P) \\
SRAM & $1 \mathrm{~KB}$ (Atmega328P) \\
EEPROM & $16 \mathrm{MHz}$ \\
Clock Speed & 13 \\
LED_BUILTIN & $68.6 \mathrm{~mm}$ \\
Length & $53.4 \mathrm{~mm}$ \\
Width & $25 \mathrm{~g}$ \\
Weight & \\
C. Matlab &
\end{tabular}

MATLAB ${ }^{\circledR}$ is a programming platform designed specifically for engineers and scientists. The heart of MATLAB is the MATLAB language, a matrix-based language allowing the most natural expression of computational mathematics.

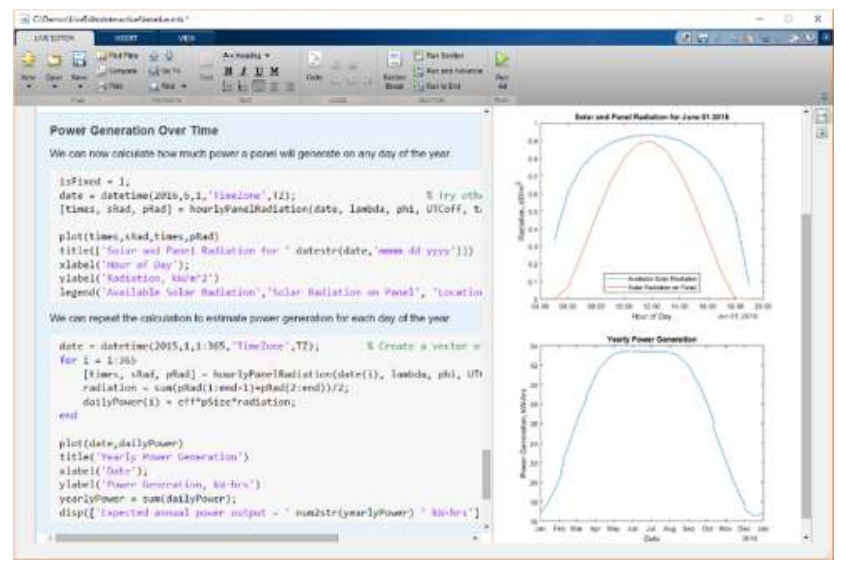

Fig 4. Matlab Min Preview

Using MATLAB, you can:

- Analyze data

- Develop algorithms

- Create models and applications

The language, apps, and built-in math functions enable you to quickly explore multiple approaches to arrive at a solution. MATLAB lets you take your ideas from research to production by deploying to enterprise applications and embedded devices, as well as integrating with Simulink ${ }^{\circledR}$ and Model-Based Design. 


\subsection{Methode}

\section{a. Circuit Schematic}

The main schematic of our proposed system has been given to the following figure where the interfaces between the major components are shown. The output data pins of the particular sensors were interfaced with the analog input pins of the Arduino board to deliver the analog signals that were generated from the sensors due to interaction of the toxic gases to the chemical layer.

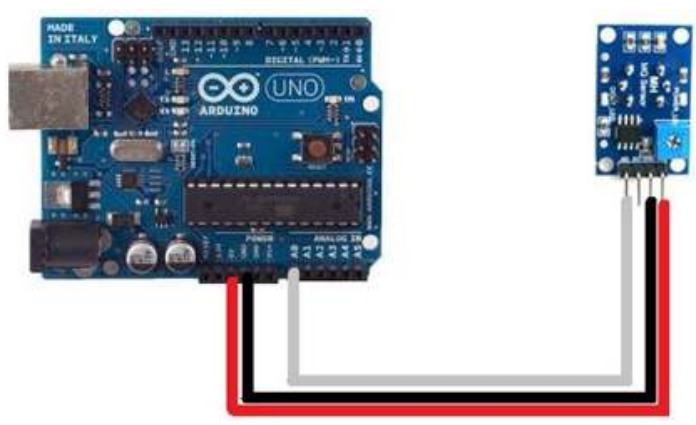

Fig. 5 Circuit Schematic of the system

In Fig. 5 it shows the establishment of our proposed system. The system was powered on via USB A to B cable and the other end of the cable can be connected to any $5 \mathrm{~V}$ power source such as adapters or USB power banks. The system turns on automatically sensing the power and shows the outputs values of gas emission via Serial Cable to the Matlab GUI.

b. Flowchart

The flowchart of our purposed system is shown below in Fig 6. 
c. Code and Callibration

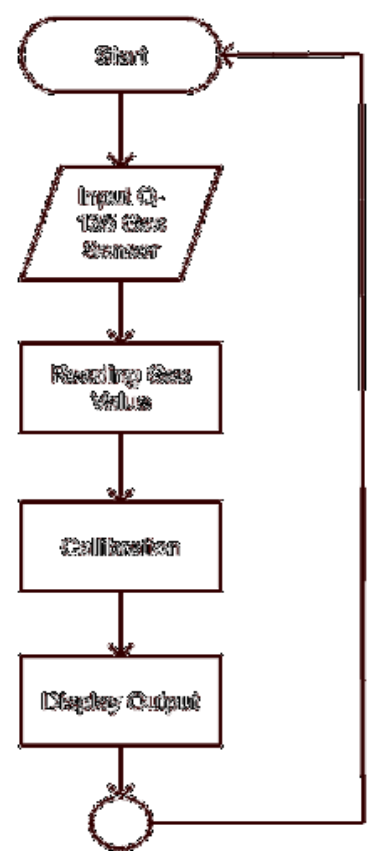

Fig 6. Flowchart of the system

The output from sensor readings will be calibrated to ppm (parts per million) to get the desired results. With each type of gas emission going through each calibration formula, for example Carbon Monoxide

Example of Matlab programming.

Function $\mathrm{x}=$ getCalibratedCO $(\mathrm{t}, \mathrm{h})$

$\mathrm{c}=$ MQ135Const;

$\mathrm{x}=\mathrm{c} . \mathrm{scaleFactorCO} *(($ getCorrectedResistance $(\mathrm{t}$,

h)/getCorrectedRZeroCO $($ getCorrectedResistance $\left.(t, h)))^{\wedge}(-c . e x p o n e n t C O)\right)$; end

After the callibration process, it will be plotting the output of the callibration will be processed to a main program as the result of the program.

\section{Results and Discussion}

The output values of the system are shown in the LCD device that shows the levels of these two poisonous gases in ppm. The system was tested in air conditioned rooms and in open spaces with various conditions. The data collected and represented in the tabular form in TABLE III. 


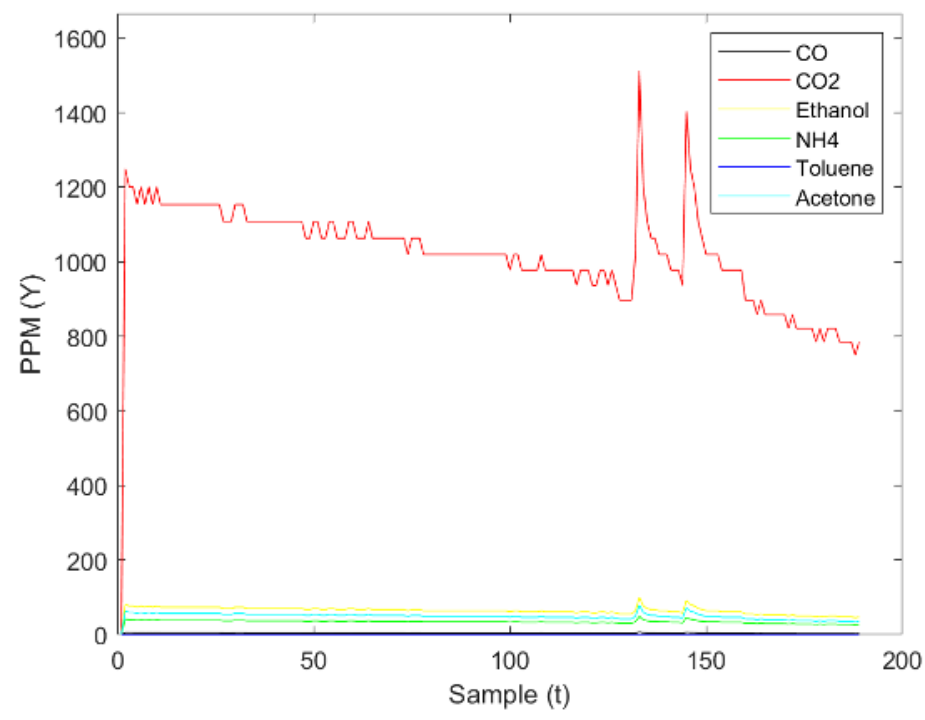

Fig 7. Air Quality in Air Conditioned Rooms

After Observing Fig 6, we can develop a relation between the amount of poisonous gases in air conditioned rooms with area and number of people. If the value of poisonous gas is denoted as $\mathrm{V}$, and the area and number of people are denoted as A and $\mathrm{N}$ respectively then we can say that, (1) From equation (1), we can say that if number of people increase then the value of ppm will increase for poisonous gases whereas the value of ppm will decrease the due to the increment of area. The extreme point for Carbon monoxide is set to $80 \mathrm{ppm}$, the carbon dioxide was set to $1200 \mathrm{ppm}$ in our system, and the othe gas no more than carbon monoxide.

\section{Conclusion}

In this paper, we proposed Microcontroller Based on Continuous gas emissions in air Monitoring System. We have made the system compact and cost efficient and displayed the values of $\mathrm{CO}, \mathrm{CO} 2$, Ethanol, NH4, Toulene and Acetone in Matlab. And the whole system has been designed less power consuming, handy, weight and easily to use. The system can be used in any industries and any companies as means of emission monitoring and air quality. Thus, it will be able to assist the industry in helping control and monitor their industrial emissions levels

\section{References}

[1] Kumar, G. Epidemiological study on effect of air pollution on human health (adults) in Delhi. Central pollution control board, Ministry of environment and forests, Delhi, India, (Jan. 2012). 
[2] Khanna, N. Measuring environmental quality: an index of pollution. Ecological Economics, vol-35(2),pp. 191-202, 2000. DOI: 10.1016/S0921-8009(00)00197-X

[3] N. Kularatna and B. H. Sudantha, "An Environmental Air Pollution Monitoring System Based on the IEEE 1451 Standard for Low Cost Requirements," IEEE Sensors Journal, 8(4), pp. 415-422, 2008.

[4] B. O’Flynn, F. Martínez-Català, S. Harte, C. O’Mathuna, J. Cleary, C. Slater, F. Regan, D. Diamond and H. MurpHy, "SmartCoast: A Wireless Sensor Network for Water Quality Monitoring," In Proceedings of the 32nd IEEE Conference on Local Computer Networks, 2007, pp. 815-816.

[5] M. Ljubojevic, M. Zoric, M. Simic and Z. Babic, "Quality of Life Context Influence Factors improvement Using Houseplants and Internet of Things," Presented at the IEEE BlackSeaCom conference, 6-9 June 2016, Varna, Bulgaria.

[6] T. E. of E. Britannica, "Carbon dioxide," Encyclopædia Britannica, 03-Jan-2018. [Online]. Available:

[7] https://www.britannica.com/science/carbon-dioxide.[Accessed: 14-April-2019].

[8] "What are safe levels of $\mathrm{CO}$ and $\mathrm{CO} 2$ in rooms?" [Online] . Available: https://www.kane.co.uk/knowledgecentre/what-are-safe-levels-of-co-and-co2-inrooms.[Accessed: 18-April-2019].

[9] "Where to use MQ-135 sensor." [Online]Available:https://components101.com/sensors/mq135-gas-sensor-for-airquality[Accessed: 18-May-2018].

[10]HANWEI ELECTRONICS CO., LTD, "Semiconductor Sensor for Carbondioxide," MQ-135 datasheet

[11]IoT platform - thethings.Io. 2016 . http://thethings.io. Accessed: 2016- 06- 14.

[12]National Air Quality Index. Central pollution control board (2015).

[13]D'Ausilio, Alessandro. Arduino: A low-cost multipurpose lab equipment. Behavior research methods, vol- 44(2), pp. 305-313, 2012.

[14]Banzi, M. and Shiloh, M. Make - Getting started with Arduino: The open source electronics Prototyping platform, second edition. Make:Books/O’Reilly, United States, 2015.

[15]ElShafee, Ahmed, and Karim Alaa Hamed. Design and implementation of a WIFI based home automation system. World academy of science, engineering and technology, vol- 68, pp. 2177-2180, 2012

[16]N. Kularatna and B. H. Sudantha, "An Environmental Air Pollution Monitoring System Based on the IEEE 1451 Standard for Low Cost Requirements," IEEE Sensors Journal, 8(4), pp. 415-422, 2008.

[17]M. Ljubojevic, M. Zoric, M. Simic and Z. Babic, "Quality of Life Context Influence Factors Improvement Using Houseplants and Internet of Things," Presented at the IEEE BlackSeaCom conference, 6-9 June 2016, Varna, Bulgaria. 